\title{
ANÁLISE DAS CONVENÇÕES DISCIPLINARES EMPREGADAS PELA ORGANIZAČÃO CRIMINOSA, AUTODENOMINADA PRIMEIRO COMANDO DA CAPITAL, EM SEMELHANÇA AOS ASPECTOS DOUTRINÁRIOS DE INTELIGÊNCIA DE SEGURANÇA PÚBLICA
}

\section{doi> 10.33726/akdpapers2447-7656v9a62020p37-52}

VIEIRA, Álvaro de Souza ${ }^{1}$

RESUMO: O objetivo do presente artigo é apresentar e descrever as posturas e ações de cunho disciplinar orientadas pela autodenominada organização criminosa Primeiro Comando da Capital - PCC, no que versa à sua persuasão em meio aos seus integrantes, bem como dentro de comunidades outrora inseridas. Ainda, analisam-se aspectos da efetividade perante o emprego - em analogia e semelhança -, no tocante a elementos existentes na Doutrina Nacional de Inteligência de Segurança Pública (2009), ainda que de forma experimental e inconsciente. As concepções apresentadas no presente artigo, estas, examinadas sobre os conceitos baseados no entendimento legal de crime e organização criminosa, foram postas em semelhança aos juízos dispensados pela citada organização criminosa, com o intuito de promover um paralelo construtivo e reflexivo, a fim de demonstrar a pendente e necessária intervenção do Estado perante o assunto.

PALAVRAS-CHAVE: Organização Criminosa, Inteligência, Primeiro Comando da Capital, Disciplinar, Segurança Pública

ABSTRACT: The purpose of this article is to present and describe the disciplinary actions and attitudes guided by the self-styled criminal organization Primeiro Comando da Capital (PCC), regarding its persuasion among its members, as well as within communities previously inserted. Still, aspects of effectiveness in relation to employment are analyzed - In analogy and similarity -, with respect to elements existing in the National Doctrine of Intelligence of Public Security (2009), although in an experimental and unconscious way. The conceptions presented in the present article, these, examined on the concepts based on the legal understanding of crime and criminal organization, were put in similarity to the judgments dispensed by the aforementioned criminal organization, in order to promote a constructive and reflective parallel, in order to demonstrate the pending and necessary State intervention in the matter.

KEYWORDS: Criminal Organization, Intelligence, Primeiro Comando da Capital, Disciplinary, Public security

\footnotetext{
${ }^{1}$ Discente de Pós-Graduação, no Curso de Inteligência Policial, pela FAVENI - Faculdade Venda Nova do Imigrante. Agente Policial Penal. Analista de Inteligência AIIP/DEPEN-MG/SEJUSP, e-mail: designalvaro@yahoo.com.br.
} 


\section{I - INTRODUÇÃO}

O presente artigo se propõe a promover uma análise sobre as atividades de cunho disciplinar - face ao conceito legal de crime vigente no Brasil -, promovidas pela organização criminosa autodenominada Primeiro Comando da Capital - PCC $^{2}$, esta, com expressiva atuação e abrangência em território nacional e adjacências, incorporada de forma estruturada e institucionalizada.

Noutro giro, verifica-se que tais posturas "correcionais" correspondem evidentemente, em semelhança -, a elementos pertencentes à Doutrina Nacional de Inteligência de Segurança Pública $(2009)^{3}$, esta que será pauta comparativa para desenvolvimento do presente texto.

O fortalecimento e o controle social que o PCC exerce face aos seus faccionados, reclusos ou não, vêm desafiando autoridades e agentes de segurança pública, mormente pelo fato de que seus reflexos são projetados nas comunidades em que o mesmo se insere. Logo, atribui-se a prospecção de êxito à observação de aspectos/elementos presentes no universo da estratégia, estes, no caso a ser percorrido, análogos às rotinas da atividade de Inteligência de Segurança Pública - ISP, como, por exemplo, a preocupação com a proteção orgânica e de informações, ainda que envolvidas pela natureza escusa.

Nesse ínterim, ações de autoridades, governantes e até mesmo da sociedade civil organizada se fazem necessárias, a fim de que haja um coerente e pontual ato racional, frente a tal absurdez a serviço do crime. $\mathrm{E}$, aqui, racionalizar a problemática é um princípio para tal embate.

Posto isto, vale salientar, que, para a elaboração da presente pesquisa, o método de pesquisa empregado foi o qualitativo, também, tendo como suporte, pesquisas bibliográficas consubstanciadas ao tema proposto, metodologias que melhor se ajustam ao modus operandi usualmente observado pela citada organização criminosa, o que nos permite firmar maior apoio no escopo da Lei de Organizações Criminosas (Lei n. 12.850/13).

\footnotetext{
${ }^{2}$ Que também terá a referência pela sigla PCC e/ou pela nomenclatura Comando.

${ }^{3}$ As análises constantes no presente artigo contemplam a Doutrina Nacional de Inteligência de Segurança Pública de 2009, haja vista a ampla divulgação e abertura de acesso de conteúdo, sobretudo através sítios existentes na Internet. As versões publicadas em 2014 e 2016 são classificadas em grau de sigilo.
} 


\section{II - CONCEITOS PAUTADOS EM LEGISLAÇÃO}

Para um franco desenvolvimento, verifica-se uma necessidade de promover esclarecimentos sobre alguns conceitos tidos como legais, haja vista tratarem-se de questões atinentes e próprias de organizações criminosas, ou seja, o chamado "crime organizado".

\section{II.1 - CRIME}

Materialmente ${ }^{4}$, o crime inclina-se àquilo que é passível de punição em seu conteúdo. Formalmente ${ }^{5}$, molda-se à definição nominal: a relação do termo com aquilo que ele representa. Por fim, na faceta analítica ${ }^{6}$, a apreciação corresponde aos elementos que dão forma ao crime. Senão, vejamos o conceito atribuído a crime, trazido pelo Decreto-Lei ํo 3.914, de 09 de dezembro de 1941, Lei de Introdução do Código Penal (Decreto-Lei n. 2.848, de 07-12-1940) e da Lei das Contravenções Penais (Decreto-Lei n. 3.688, de 03 de outubro de 1941), em seu artigo 1丷:

Art. $1^{\circ}$ - Considera-se crime a infração penal que a lei comina pena de reclusão ou de detenção, quer isoladamente, quer alternativa ou cumulativamente com a pena de multa; contravenção, a infração penal a que a lei comina, isoladamente, pena de prisão simples ou de multa, ou ambas, alternativa ou cumulativamente (BRASIL, 1941).

Em suma, segundo o direito penal brasileiro, o termo "crime" trata, antes de tudo, de um fenômeno social, não estático, imutável ou isolado num determinado tempo, e sim, envolvidos por valores e até mesmo econômicos, que Ihes são bem peculiares.

\footnotetext{
${ }^{4}$ Atento a Luiz Alberto Machado (1987, p. 78), o conceito material de crime busca o que há de mais importante num delito, imputando as ditas condutas.

5 Juridicamente parafraseando, parte do pressuposto de que crime consiste numa violação à lei penal.

${ }^{6}$ Análise de causa e finalidade do crime.
} 


\section{II.2 - ORGANIZAÇÃO CRIMINOSA}

Pautado pelo conceito fixado na Lei $\mathrm{n}^{\circ} \mathbf{1 2 . 8 5 0 / 1 3}$, Art. $1^{\circ}$, parágrafo $1^{\circ}$, a definição de organização criminosa é, assim, estabelecida:

Art. 1ํㅡㄹ Esta Lei define organização criminosa e dispõe sobre a investigação criminal, os meios de obtenção da prova, infrações penais correlatas e o procedimento criminal a ser aplicado.

$\S 1^{\circ}$ Considera-se organização criminosa a associação de 04 (quatro) ou mais pessoas, estruturalmente ordenada e caracterizada pela divisão de tarefas, ainda que informalmente, com objetivo de obter, direta ou indiretamente, vantagem de qualquer natureza, mediante a prática de infrações penais, cujas penas máximas sejam superiores a 04 (quatro) anos, ou que sejam de caráter transnacional (BRASIL, 2013).

Observa-se que, como uma forma de esboçar significantes de um poder simbólico $^{7}$, segundo Oliveira (2015, apud LIMA, 2014, p. 473), algumas organizações surgiram da necessidade das pessoas reunirem-se, não objetivando - ordinariamente - a prática de crimes, e sim, como tática para o combate de possíveis desigualdades sociais vigentes.

Insta acrescentar que tal fenômeno pôde ser considerado, em alguns ajustes característicos (em semelhança), a ações alusivas em correspondência à atividade de Inteligência ${ }^{8}$, ainda que não o pudesse classificar dessa forma, no sentido de promover a proteção de um determinado organismo ${ }^{9}$ e seus interesses (ainda que escusos), em analogia ao ramo da atividade de Inteligência de Segurança Pública, cognominado contrainteligência.

Contrainteligência $(\mathrm{Cl})$ é o ramo da atividade de ISP que se destina a produzir conhecimentos para proteger a atividade de Inteligência e a instituição a que pertence, de modo a salvaguardar dados e conhecimentos sigilosos e identificar e neutralizar ações adversas de qualquer natureza. $\mathrm{A} \mathrm{Cl}$ assessora também em assuntos internos de desvios de conduta, relacionados à área de Segurança Pública (BRASIL, 2009).

As organizações criminosas executam métodos peculiares, sendo que, com o Primeiro Comando da Capital (PCC), ocorreu fato semelhante.

\footnotetext{
${ }^{7}$ Segundo Bourdieu, os sistemas simbólicos exercem um poder estruturante, na medida em que são estruturados, uma forma transformada e legitimada de outras formas de poder.

${ }^{8}$ Consiste na produção e proteção de conhecimentos.

${ }^{9}$ Como um dos 02 (dois) ramos da atividade de Inteligência de Segurança Pública, a contra inteligência destina-se a produzir conhecimentos para neutralizar as ações adversas, e proteger a atividade e a instituição a que pertence.
} 


\section{III - O PRIMEIRO COMANDO DA CAPITAL (PCC) E SEU SURGIMENTO}

Embora, teoricamente tenha a sua origem no Estado de São Paulo, tratase da organização criminosa com atuação em praticamente todos os Estados brasileiros, apresentando ramificações em países limítrofes ${ }^{10}$, influenciando ainda outros grupos em prol da constância da atividade criminosa e ideológica.

Insurgiu, no ano de 1993, via sistema prisional, no Centro de Reabilitação Penitenciária de Taubaté/SP, estabelecimento penal que, à época, custodiava presos tidos como de alta periculosidade ${ }^{11}$ : estava disposto um novo formato de "combater a opressão do Estado", reverberando como uma multinacional a serviço do crime, enfaticamente nos dias atuais.

\section{III.1 - O PCC E SUA METODOLOGIA DISCIPLINAR}

Outrossim, em conformidade com relatos de entes das comunidades de Inteligência de Segurança Pública ${ }^{12}$, bem como análises históricas e literárias, - Primeiro Comando da Capital (PCC) exerce papel característico (e estratégico) nas lacunas deixadas pelo poder público, no que tange a acompanhar e disciplinar ações, seja em meio à comunidade inserida, seja na regulação de seus integrantes/membros: onde o poder público não chega, o crime organizado tende a suprir.

O Estado brasileiro, na prospecção, desenvolvimento e aplicação de políticas públicas, destoa quanto a questões relativas à dignidade humana, mormente por tratar-se de fundamento primeiro e último relacionado na Constituição Federal Brasileira e na Declaração Universal dos Direitos Humanos, por exemplo. Esta última apresenta como lema os princípios de igualdade, liberdade, paz e justiça, ou seja, o moto oficial adotado e

\footnotetext{
${ }^{10}$ Bolívia, Colômbia, Peru, Chile, Venezuela, Paraguai, Argentina e Guiana Francesa são alguns países.

${ }^{11}$ Parafraseando Casaletti (2017), num dia de campeonato futebolístico na Unidade Prisional, oito (08) custodiados, dentre eles, José Marcio Felício ("Geleião"), Cezar Augusto Roriz ("Cezinha"), Idemir Carlos Ambrósio ("Sombra"), e, posteriormente, Marcos Willians Herbas Camacho ("Marcola"), discutiram com outros detentos, o que, em suma, provocou duas mortes. Tal fato gerado fomentou uma reivindicação contra as mazelas existentes no sistema carcerário, bem como uma forma de protestar contra o Massacre do Carandiru, meses antes sucedido.

${ }^{12}$ Também, será utilizada a sigla ISP.
} 
amplamente propagado pela citada organização criminosa em todas as esferas.

Ideologicamente, também adequa-se em similitude aos pressupostos apresentados por Guy Debord (1997), expondo o conceito de Sociedade do Espetáculo, avesso à alienação de perversão e aceitação passiva perante a vida moderna e valores estabelecidos a partir do capital.

Destarte, sobre as questões pertinentes aos acordos disciplinares ou de controle, com o emprego de tal postura, vale-se considerar que o PCC tem estabelecido a atmosfera de uma sociedade paralela, plotado como uma reconfiguração do Estado ou do governo, moldando-se, a exemplo, à teoria da Cidade dentro das Cidades $^{13}$, na perspectiva de promover condições, normas e critérios pré-estabelecidos, ainda que reclinadas ao fenômeno do crime.

Posto isto, considerando o acompanhamento das ações impulsionadas pela organização criminosa supracitada, foi verificada a existência de departamentos $^{14}$, com atribuições bem definidas, que -, sob a coordenação e supervisão de uma cúpula -, são comissionados à promoção e exercício de um controle disciplinar por questões de interesses coletivos inerentes ao grupo, seja em ambientes carcerários e/ou até mesmo nas ruas, face aos seus integrantes oficiais e em meio às comunidades as quais o crime está inserido. Eis a proficiência do dito "Quadro Disciplinar" ${ }^{15}$ do PCC, funcionando como uma espécie de subsistema ${ }^{16}$.

Mediante a clara observação de itens constantes em regimentos próprios ${ }^{17}$, situados num entendimento bastante peculiar sobre o conceito de crime, aferese que a organização criminosa pronuncia-se na forma de "julgamentos", no

\footnotetext{
${ }^{13}$ Aqui, refere-se ao conceito estipulado por Park (1976), conceito em que a cidade deveria ser formulada como algo além do que uma aglomeração de pessoas, cujos costumes, hábitos e práticas sociais dos habitantes fossem compreendidos não a partir de suas formas física e funcional, mas como um espaço "vivo", dotado de um "espírito" próprio.

${ }^{14}$ Segmentos, com funções bem definidas e interligadas.

15 O quadro é responsável por questões disciplinares entre faccionados e/ou a comunidade em que está inserido, a fim de coibir a intervenção de agentes de segurança pública. Trata-se da inclusão de uma espécie de Estado Paralelo. Interessante observar que a própria sociedade civil organizada, expressa por comunidades minoritárias, procura e espera por posturas do "Quadro Disciplinar".

${ }^{16}$ Muito semelhante à organização da atividade de ISP, o Quadro Disciplinar funcionaria como um Subsistema (o Sistema seria o próprio PCC).

${ }^{17}$ Estatuto do PCC, Regimento Disciplinar, Cartilha de Condução.
} 
que versa a respostas decisivas a questões disciplinares - sob o prisma da criminalidade.

Regido por uma espécie de Estatuto $^{18}$ próprio, o PCC, estruturalmente organizado, exerce controle ideológico perante os seus "controlados", hierarquizados por um conjunto normativo de organização, disciplina e funcionamento vertical/horizontal, estas, impostas a todos os níveis de integração e atuação do grupo. Além disso, revela uma preocupação do grupo criminoso em estabelecer regras no meio carcerário, no bojo do tipo desejável de funcionamento das prisões (a não tirania), promovendo uma postura de enfrentamento perante autoridades, leis e Estado.

\section{III.2 - À SEMELHANÇA DOS ASPECTOS DE PROTEÇÃO ORGÂNICA}

Observa-se que esse tipo de controle é, em extremo, articulado, baseado em princípios adotados pelo público criminoso, num escopo semelhante a uma atividade de Inteligência ${ }^{19}$, empregada por muitos entes organizados e/ou institucionalizados.

Ainda, outra normativa é seguida pela membresia, a chamada Cartilha de Condução ${ }^{20}$, numa interlocução apresentada como "legítima" pelo público delinquente. Em suma, trata-se de um conjunto de regras impositivas, contemplando punições para integrantes da organização criminosa, seja por possibilidade de falta (no caso de verificação de infração ou não observância às normas vigentes) ou por "justiça" (caso algum membro solicite uma ação ao se sentir lesado).

Nessa estruturação arrumada, destacam-se as divisões de tarefas, com 0 intuito de prover a organização criminosa nas mais variadas esferas, por meio de posturas consideradas nocivas, repudiadas perante o ordenamento jurídico brasileiro, a saber: departamentos distribuídos em setores, como por exemplo,

\footnotetext{
18 Trata-se de um documento, contendo um conjunto de normas e conceitos a serem observados e reproduzidos pelos integrantes da organização criminosa. Possivelmente, a criação do Estatuto se deu a partir de 1997, e apresenta características que o aproxima de outros conjuntos de regras de grupos similares (JACOBS, 1974). Atualmente, é um conjunto de 18 (dezoito) itens - versão 2019.

${ }^{19}$ Sobretudo, doutrinariamente à Inteligência de Segurança Pública.

20 Atualmente, contempla 32 (trinta e dois) itens, que vão desde abandono, atos de vandalismo, “caguetagem”, extorsão, pederastia, entre outros.
} 
o setor de natureza financeira (controle financeiro); o de cadastro (controle de ingressos); "salveiro"21 (dissipadores de mensagens e ordens); "progresso"22 (responsáveis pela execução de tarefas fins), entre outros, e a serviço de negócios escusos ou omissos. Tais atribuições são observadas como específicas, intransferíveis e indelegáveis entre a irmandade. Insta considerar que o PCC conspira para com o zelo do membro, onde se torna intolerante ao grupo qualquer questionamento face às lideranças.

Os denominados "resumos"23 são compostos por indivíduos faccionados em gradações, isto é, com atribuições em patamares hierarquizados, inclusos, por exemplo, nos setores "Geral de Estados e Países" ${ }^{24}$ e "Geral de Estados"25. Em conformidade com dados disponíveis, possivelmente, a estrutura hierarquizada em sua gradação máxima é denominada "Sintonia Final"26.

Nesse diapasão, no afã da ideia de pertencimento, de forma providencial e proposital (deixando claro que se trata de um viés ilustrativo em comparação e analogia), o PCC tem se utilizado de fundamentos doutrinários constantes na Doutrina Nacional de Inteligência de Segurança Pública (2009), como por exemplo, a característica da atividade de ISP qualificada de Assessoria, que a dignifica como órgão de assessoramento, produzindo conhecimentos para o processo decisório e para auxiliar as polícias em suas atividades (BRASIL, 2009).

${ }^{21}$ Responsáveis pela transcrição, transmissão e salvaguarda dos "salves" emanados pelo comando da ORCRIM. Possivelmente, é considerada hierarquicamente na estrutura do PCC como sendo uma posição de staff.

${ }^{22}$ Função inclinada ao termo progressão, visando promover a evolução das atividades ilícitas (tráfico de drogas e roubo), a fim de manter a saúde financeira da organização criminosa, também, através de arrecadações compulsórias entre membros. Acompanha e organiza a logística de distribuição de entorpecentes.

${ }^{23}$ Possui também o propósito de assessoramento.

24 Trata-se de um conselho formado por integrantes graduados da organização criminosa, cuja responsabilidade versa sobre a propagação da ideologia do PCC nos Estados na Unidade Federativa, idealizando o chamado progresso das atividades desenvolvidas pelo grupo faccionado. Mantém contato direto e irrestrito com o quadro "Geral do Estado", se inteirando sobre questões gerais para repasse a setores verticais superiores.

${ }^{25}$ Inicialmente, era chamada de torres. Trata-se de um conselho. Tais indivíduos exercem posição de liderança entre os membros da ORCRIM e estabelecem contatos com as demais "gerais" existentes em presídios e na rua. Dentre suas funções, está a transmissão de informação e a criação de normas e diretrizes quanto os procedimentos, bem como o controle e a disciplina dos membros que se encontram presos ou em liberdade.

${ }^{26}$ É composto por integrantes de diversos Estados da Federação, a fim de analisar tratativas da ORCRIM em âmbito nacional. 
O Quadro Disciplinar tem desenvolvido tratativas no sentido de promover a integração de indivíduos pertencentes ao bojo da criminalidade, comumente conhecidos como "batismos" ${ }^{27}$, pautados por exigência de requisitos, sendo estes, mais uma vez, em semelhança aos processos de organização da atividade de ISP, um Recrutamento Administrativo "às avessas" ${ }^{28}$. O que chama a atenção é que tal rito tem ocorrido num formato desenfreado em determinadas épocas e com interesses bem definidos, a fim de expandir a marca PCC, adotando a modalidade branding ${ }^{29}$, sobretudo por não estar submetido a nenhum protocolo de controle compulsório, a não ser que fira conceitos preciosos perante o universo da criminalidade.

Estrategicamente, percebe-se uma alternativa recorrente da organização criminosa em declinar responsabilidades típicas do Quadro Disciplinar a indivíduos sem antecedentes policiais, prisionais ou processuais, bem como a adolescentes infratores, potenciais aspirantes a uma vaga no grupo. Tal protocolo se destina a bloquear de autoridades e Agentes de Segurança Pública qualquer suspeição que, eventualmente, possa se transformar em dissabor, como por exemplo, em caso de ataques contra servidores, repartições públicas, atos de subversão, entre outros, corroborando com a sensação de morosidade por parte do Estado, comumente constituída no imaginário coletivo social, independente de condição financeira ou classe social.

Contudo, como consequência do procedimento de integração na organização criminosa, tanto os novos como tradicionais membros - num molde ritualístico -, estão submetidos à disciplina do Comando, ou seja, cada postura, seja em ação ou negligência, de um integrado, é cuidadosamente analisada pela cúpula responsável pelo setor, face aos manuais a ser seguidos

\footnotetext{
${ }^{27}$ Trata-se do ritual de ingresso na ORCRIM. Via de regra, contempla alguns itens obrigatórios de triagem para quem pleiteia, tais como: local de batismo, data, "padrinhos", "quebrada de origem e atual", últimas funções na ORCRIM, se possui dívidas ou pendências, etc. O candidato NÃO se tornará membro caso haja alguma pendência reprovável pelo grupo, cabendo a tal resolve-la.

${ }^{28}$ Verifica-se que a criminalidade, através do PCC, tem declinado exigências quanto ao perfil daquele que pleiteará a integração na ORCRIM. Semelhante à atividade de ISP, tenciona a verificação de antecedentes (do crime) e compatibilidades com a "atividade" criminosa.

${ }^{29}$ Verifica-se a inclinação da ORCRIM em reproduzir o conceito de licença e direito do uso de marca, como franquia a serviço do crime. Curiosamente, há relatos em documentos que traduzem que foram realizados os "batismos de fortalecimento", ou seja, o recrutamento de indivíduos estritamente por questões financeiras ou com objetivos determinados.
} 
rigorosamente, o que poderá conceber em possíveis faltas e promoção de juízos, convencionando-se uma dita atmosfera de ética e moral ${ }^{30}$ em antítese, face aos critérios que circundam os episódios do crime, promovidas pela organização criminosa.

Em correlação, as conjecturas propostas por Émile Durkheim (1987), aludidas ao processo educativo, aqui, transplantado para os jeitos do crime, tal atmosfera é inerente à construção do integrante ou faccionado, adstrito às diferenças culturais, familiares e de classe, constituindo-se num sistema de ideias, sentimentos e hábitos que exprimem o sentimento de grupo. Tal fenômeno se consolida, projetando-se segundo o Estatuto do PCC:

[...] 3 Item: Todos os integrantes do Comando têm por direito expressar sua opinião e têm o dever de respeitar a opinião de todos. Sabendo que dentro da organização existe uma hierarquia e uma disciplina a ser seguida e respeitada. Aquele integrante que vier a causar divisão dentro do Comando, desrespeitando esses critérios, será excluído e decretado. [...] 12 Item: O Comando não tem limite territorial, todos os integrantes que forem batizados são componentes do Primeiro Comando da Capital, independente da cidade, estado ou país, todos devem seguir a nossa disciplina e hierarquia do nosso estatuto (PCC, 2019).

Dessa maneira, atribui-se que as ditas regras disciplinares são, segundo o Estatuto, para serem observadas e cuidadosamente seguidas por todos os membros da organização criminosa, independentemente da hierarquia, sejam indivíduos em liberdade, egressos ou custodiados em Sistemas Penais.

13 Item: O Comando não tem nenhuma coligação com nenhuma outra facção, vivemos em harmonia com facções de outros estados, quando algum integrante de outra facção chegar em alguma cadeia nossa o mesmo será tratado com respeito e terá o apoio necessário, porém, queremos o mesmo tratamento quando o integrante do Comando chegar preso em outro estado em cadeias de outras facções e se algum integrante de outra facção de outro estado desrespeitar a nossa disciplina em nossa cadeia, vamos procurar a sintonia responsável pelo mesmo e juntos procurarmos a solução e se ocorrer de um irmão nosso estar desrespeitando, a busca da solução será da mesma forma. Deixamos bem claro que isso se trata de facções de outro estado que seja amiga do Comando. 14 Item: Todos os integrantes serão tratados com igualdade, sendo que a nossa luta é constante e

\footnotetext{
${ }^{30}$ Interação sociocultural do crime.
} 
permanente, seus méritos e atitudes serão avaliadas dando prioridade para aquele que merece, esclarecendo que méritos não é sinônimo de acomodações e impunidade diante da nossa luta, tratando com igualdade para os iguais e desigualdade para os desiguais (PCC, 2019).

Além disso, semelhantemente ao exemplo anterior, na perspectiva da Doutrina Nacional de Inteligência de Segurança Pública - DNISP, no arcabouço da Reunião de Dados ${ }^{31}$, pôde-se inferir que indivíduos integrados à organização criminosa PCC têm empregado a mesma metodologia, além das Ações de Inteligência ${ }^{32}$, do tipo Ações de Coleta Primária ${ }^{33}$, mormente examinadas quando faccionados alocados no Quadro Disciplinar são incumbidos na promoção de levantamos de dados sobre Agentes de Segurança Pública ou instituições financeiras, a fim de panejarem atentados, roubos ou qualquer ação correlacionada à associação de prática criminosa, por exemplo.

No sistema carcerário brasileiro - multiplicador desenfreado e público principal da ideologia do PCC - não é diferente. A fim de que as ações intracárcere de interesse da organização criminosa sejam concebidas - sem ou com a interferência mínima de Agentes Públicos -, os custodiados têm usufruído da modalidade chamada Desinformação. Para a DNISP (2009), tratase de uma Ação de Busca instituída para, intencionalmente, confundir alvos, com o intuito de que tais cometam equívocos de apreciação de informações, ação esta muito utilizada no ramo da contrainteligência, segmentada pela Proteção Orgânica.

Ainda, em semelhança à Segurança Orgânica - SEGOR, tal organização criminosa supracitada tem aplicado medidas defensivas e preventivas, a fim de

\footnotetext{
${ }^{31}$ Segundo a DNISP (2009), é a fase do CPC na qual as AI procuram obter os dados necessários, realizando, metódica e sistematicamente, ações que lhes possibilitem produzir o conhecimento.

${ }^{32}$ Segundo a DNISP (2009), são todos os procedimentos realizados por uma AI, para dispor dos dados necessários e suficientes para a produção do conhecimento, centrados, de um modo geral, em dois tipos de ações de Inteligência: Ações de Coleta e Ações de Busca.

33 Segundo a DNISP (2009), são todos os procedimentos realizados por uma AI, ostensiva ou sigilosamente, a fim de obter dados depositados em fontes abertas, sejam elas originadas ou disponibilizadas por indivíduos e órgãos públicos ou privados. Coleta Primária: envolve o desenvolvimento de ações de ISP para obtenção de dados e/ou conhecimentos disponíveis.
} 
que os interesses do grupo funcionem em harmonia, mormente no que versa sobre a salvaguarda de documentação ${ }^{34}$.

Faccionados, em setores específicos com tarefas indelegáveis, estão responsáveis pelo acondicionamento seguro de dados, evitando que Agentes de Segurança Pública ou até mesmo veículos de comunicação de massa tenham acesso ao conteúdo reservado, o que poderá ser classificado no presente artigo como "vazamento", como por exemplo, informações de quantitativo de indivíduos integrados ao grupo, quantitativo de indivíduos excluídos, contabilidade oriunda de comercialização de entorpecentes, aquisição de armamento, entre outros. Caso tais dados sejam expostos, o membro incumbido pela proteção poderá ser submetido a procedimentos disciplinares.

Muito comumente, sobretudo a partir da convenção de aplicativos de mensagens instantâneas e programas de computação, indivíduos vinculados à organização criminosa PCC se comportam em conformidade com duas medidas de segurança presentes na DNISP (2009), denominadas de Segurança das Comunicações e Telemática e Segurança da Informática, a fim de garantir que tais dados estejam preservados para consultas futuras, bem como o seu acesso controlado.

Observa-se também nas convenções aplicadas pelo PCC que, ainda que haja o entendimento que seja de forma indireta e/ou não-técnica, percebe-se traços de Segurança Ativa - SEGAT ${ }^{35}$ e Inteligência Policial ${ }^{36}$, através do advento da perspectiva de identificação, análise e tratativas para a neutralização de ações adversas que possam porventura frustrar objetivos escusos e/ou omissos em desfavor do grupo criminoso.

Sobretudo dentro das Unidades Prisionais, por amostragem, as convenções para que o fluxo do tráfico de drogas seja contínuo e rentável, são

\footnotetext{
${ }^{34}$ Aqui, pode-se inferir como o segmento da Segurança da Documentação, com vistas à proteção dos documentos produzidos pela organização criminosa.

${ }^{35}$ Segundo a DNISP (2009), é o conjunto de medidas de caráter eminentemente ofensivo, destinadas a detectar, identificar, avaliar, analisar e neutralizar as ações adversas de elementos ou grupos de quaisquer naturezas dirigidas contra a sociedade e o Estado.

${ }^{36}$ Aqui, os pressupostos da Inteligência Policial destinam que, através da Produção do Conhecimento, têm-se a possibilidade de agir na modalidade de prevenção, resultante da análise, padrão muito semelhante observado no PCC, através da produção e publicação dos "salves", a fim de assessorar a cúpula criminosa.
} 
minuciosamente observadas e conduzidas por criminosos faccionados ditos "mais experientes no crime" ou com ampla "bagagem criminal", a fim de coibir a intervenção de gestores, Agentes de Segurança Pública e autoridades. Aqui, nesse sentido, existe uma preocupação na manutenção do fluxo, pois, caso algo inesperado ocorra, por negligência ou despreparo, mais uma vez, o Quadro Disciplinar promoverá uma resposta, atribuindo um juízo, segundo projeções constantes em manuais.

E, por citar algumas características e especificidades que aqueles que pleiteiam a integração no PCC necessitam ter, no que tange ao quesito profissionalismo, verificam-se semelhanças em atributos dispensados aos candidatos à atividade de ISP, sobretudo no Recrutamento Administrativo.

A seguir, trazemos à tona uma ideia de "profissionalismo", num comparativo entre a DNISP (2009) e o Estatuto do PCC, respectivamente:

Os recursos humanos a serem empregados na atividade de ISP são fundamentais para funcionamento eficaz e eficiente do SISP. O profissional de ISP, além da vocação para a atividade, terá que possuir perfil profissiográfico pré-estabelecido, vida pregressa compatível, observados os atributos, dentre outros, da voluntariedade, da ética e da moral, focados na lealdade, integridade, discrição e profissionalismo (capacidade de trabalho, dedicação, responsabilidade e cooperação) (BRASIL, 2009).

[...] 01 Item: Todos os integrantes devem lealdade e respeito ao Primeiro Comando da Capital, devem tratar todos com respeito, dando bons exemplos a serem seguidos pela massa, acima de tudo ser justo e imparcial. 02 Item: Lutar sempre pela PAZ, JUSTIÇA, LIBERDADE, IGUALDADE e UNIÃO, visando sempre o crescimento da organização, respeitando sempre a ética do crime. [...] 11 Item: Toda missão destinada deve ser concluída, será feita uma avaliação da capacidade de cada integrante indicado pela sintonia, aquele que for selecionado e aprovado [...] (ESTATUTO PCC, 2019).

Nessa linha, outras características de ISP poder-se-iam ser objeto de estudo no presente. Entretanto, a peculiaridade das que foram apresentadas demonstra a expertise com que o crime organizado tem se utilizado de pressupostos ditos legais, convencionais ou aceitáveis, na expectativa de transforma-los com serventia ao crime. 


\section{IV - CONCLUSÃO}

Em conformidade com os argumentos apresentados no presente artigo, bem como possíveis projeções, verifica-se que o crime organizado, sobretudo pelo estudo de caso, face ao PCC, têm se aprimorado na tratativa de estabelecer um portfólio para que as ações criminais empreendidas pelo grupo alcancem um patamar sobejo, tornando-as assimiláveis pela comunidade inserida, mormente pela forma inconsciente de, em semelhança, adotar elementos presentes e proeminentes de expedientes governamentais, como por exemplo, a Doutrina Nacional de Inteligência de Segurança Pública, no que corresponde à proteção orgânica.

Tal postura é, em extremo, preocupante, pois se refere às matérias técnicas que vêm sendo utilizadas por uma célula de inteligência do crime, o que se pode inferir, então, que não se sustenta meramente de um ato involuntário ou empírico, e sim, passível de rígidas análises empreendidas pelo grupo delinquente, principalmente pelo entendimento apresentado de que as organizações criminosas possuem características bem definidas quanto à estruturação, hierarquização, estabelecimento de funções e tarefas, ou seja, em extremo, institucionalizadas.

Com isso, ainda que as políticas públicas desenvolvidas pelos governos federal e estadual/distrital pretendam coibir a ação efetiva de grupos criminosos, pragmaticamente, observam-se entraves com relação às legislações vigentes: enquanto o declinar das ações de autoridades são totalmente articuladas às normas e leis constantes (legitimidade), do outro lado, a criminalidade não possui esse compromisso ou protocolo, o que tem impulsionado o fenômeno da proliferação de tais grupos, cada vez mais aceitos e presentes no imaginário coletivo, servindo de recurso paliativo entre governantes e sociedade.

Destarte, os processos cada vez menos complexos de integração de indivíduos nas organizações criminosas, socialmente, têm inaugurado e estabelecido uma atmosfera alternativa do conceito de justiça, trocada pelo sentido cada vez mais aguçado de pertencimento ${ }^{37}$.

\footnotetext{
${ }^{37}$ Nesse caso, pertencimento ao grupo criminoso.
} 
O PCC disciplina as ações do indivíduo em primeira instância; o indivíduo integrado despreza o fato de ter lesado à sociedade, ainda que tenha o pleno conhecimento daquilo que é conceitualmente aceito como crime, em nome de uma entidade que o represente, esboçando atitude voluntária.

No que tange ao universo carcerário, torna-se útil o processo de classificação dos encarcerados por meio de comissões técnicas, promovendo a análise individualizada do indivíduo privado de liberdade no cumprimento da pena. Do contrário, serão "agentes ressocializados e cooptados pela criminalidade", em "universidades do crime".

Posto isto, verifica-se a proeminente necessidade de que governantes e autoridades (contando com a capacidade reflexiva da população), bem como suas políticas públicas em educação, segurança pública e justiça, investimento e estudos em Inteligência e tecnologias, promova o enrijecer dos regulamentos legais e atos punitivos, sabendo-se de que não se trata de uma questão pontual ou inequívoca. Munir os órgãos de repressão ao crime organizado com informações úteis e fidedignas também se faz vital, a fim de permitir o correto entendimento face ao fenômeno criminoso, propondo alternativas eficazes e com oportunidade.

Igualmente, a reinauguração de medidas que combatam as ações de tal público nunca veio tão à baila, nunca foi tão desafiador para autoridades, governantes e sociedade, haja vista que se tornou inadmissível, intolerável e repulsiva à convivência - pacífica - perante um grupo minoritário que não possui legitimidade alguma perante o ordenamento jurídico, embora venha se comportando como tal. 


\section{V - REFERÊNCIAS}

BOURDIEU, Pierre, 1930 - Violência simbólica e lutas políticas. In.: Meditações pascalianas. Pierre Bourdieu; tradução Sérgio Miceli. $2^{\mathrm{a}}$ ed. - Rio de Janeiro: Bertrand Brasil, 2007. (páginas 199 a 230).

BRASIL. DECRETO-LEI № 3.914, DE 9 DE DEZEMBRO DE 1941. Planalto.gov.br. Disponível em: <http://www.planalto.gov.br/ccivil_03/decretolei/Del3914.htm>. Acesso em 16 de outubro de 2019.

BRASIL. LEI № 12.850, DE 2 DE AGOSTO DE 2013. Define Organização Criminosa e dispõe sobre a Investigação Criminal, Os meios de obtenção da prova, Infrações Penais Correlatas e o Procedimento Criminal. Disponível em: http://legislacao.planalto.gov.br/legisla/legislacao.nsf/Viw_Identificacao/lei\%201 2.850-2013?OpenDocument. Acesso em 17 de outubro de 2019.

BRASIL. PORTARIA № 22, DE JULHO DE 2009. Aprova a Doutrina Nacional de Inteligência de Segurança Pública. Diário Oficial da União: Brasília, n. 139, p. 58, 23 jul. 2009, Seção 1.

DEBORD, G. A Sociedade do espetáculo e Comentários sobre a sociedade do Espetáculo. Tradução de Estela dos Santos Abreu. São Paulo: Contraponto Editora, $1997 . \quad$ Disponível em $<$ https://faccaopcc1533primeirocomandodacapital.org/regimentos/estatuto_do_ primeiro_comando_da_capital_faccao_pcc_1533/>. Acesso em 18 de outubro de 2019.

DURKHEIM, Émile. As regras do método sociológico. São Paulo: Nacional, 1987, p. 43.

JACOBS, James B. Stateville. The penitentiary in mass society. Chicago (IL): The University of Chicago Press, 1977.

MACHADO, Luiz Alberto. Direito Criminal: Parte Geral. São Paulo: Editora Revista dos Tribunais, 1987.

OLIVEIRA, Luciano Francisco de. Crime Organizado: a geada negra. 2004. 89 f. Monografia (final de curso) - Curso de Graduação em Direito, Universidade Federal de Goiás: Goiânia, 2004. Disponível em: https://www.escavador.com/sobre/7505951/luciano-francisco-de-oliveira-novais - Acesso em 19 de outubro de 2019.

PARK, Robert. A cidade: sugestões para a investigação do comportamento humano no meio urbano. In: VELHO, Otávio (Org.). Fenômeno urbano. Rio de Janeiro: Zahar, 1973. 